\title{
Stock-return volatility persistence over short and long range horizons: Some empirical evidences
}

\author{
Kolawole Subair ${ }^{*}$; Ajibola Arewa ${ }^{2}$ \\ 1) Department of Economics, Yusuf Maitama Sule University (Formerly Northwest \\ University) City Campus, Kofa Nassarawa Road, Kano State, Nigeria. \\ 2) Department of Banking and Finance, Lagos State University, Ojo, Lagos State, \\ Nigeria.
}

*To whom correspondence should be addressed.E-mail:kolasubair@gmail.com

\begin{abstract}
In this paper, we account for memory failure or otherwise in the daily evolution of stock return and volatility within the purview of short and long ranges based on the arrival of fundamental news. This accounts for the return on assets in the current period to be a function of returns realized in the pasts. To achieve this objective, we estimated ARMA, ARFIMA, GARCH, FIGARCH and HYGARCH models. After implementing maximum likelihood estimation technique, we found out that the ARMA coefficients were not significant, the GARCH coefficients were significant and the memory coefficients in terms of ARFIMA, FIGARCH and HYGARCH were statistically significant. In the light of these, we propose the rejection of efficient hypothesis in the long range and document a single memory in volatility in the short range. The study recommends that ARFIMA and HYGARCH are the best forecasting models for return and volatility respectively in the Nigerian stock market.
\end{abstract}

Keywords: Forecasting models, Memory failure, Nigeria, Short range and long range horizons, Stock-return volatility

JEL Classification: C14, C22, C58, G17

\section{INTRODUCTION}

Changes in prices simply reflect the random arrivals of fundamental news in the stock market. Efficient Market Hypothesis (EMH) subsequently faces both theoretical and empirical challenges and gradually loses its ground just as other once-fully supported economic theories must encounter at some stages. One of the theoretical and empirical challenges is the existence of short and long memory in asset return which suggests that current returns are severely dependent on distant past realized returns. This does not only create opportunities for arbitrage profits but it also makes it possible for future returns to be predicted from past returns. The existence of long-memory properties involves the development of non-linear pricing models at the theoretical level to account for the long-memory behaviour.

As a result, Yajima (1985) concludes that if the underlying continuous stochastic processes of asset returns exhibit long memory, then the pricing derivatives by martingale models as well as the statistical inference concerning asset-pricing models based on standard testing procedures may not be appropriate. Since the introduction of models of autoregressive conditional heteroscedasticity (ARCH) by Engle (1982) and 
their generalization by Bollerslev (1986), there have been numerous extensions of this approach to modelling the short and long memory volatility properties of asset prices (Baillie,Bollerslev \& Mikkeslen, 1996).

This current study is in close tandem with the above-mentioned studies. In the study we applied batteries of ARMA and GARCH to examine the daily evolution of stock return and volatility in Nigerian stock market over short and long range horizons. We show that the long-range memory parameter is significant in the HYGARCH model, and we recommend equally that HYGARCH model is the best predictive model for speculators in Nigeria, since the HYGARCH error seems to have permanent effects on conditional volatility.

Booth \& Koutmos (1988) carried out a study to model index stock returns for four major European stock markets as conditionally heteroskedastic processes with time dependent serial correlation. They found that current returns in these markets are nonlinearly dependent on their past history. The study concluded that the periods of high (low) volatility are associated with low (high) autocorrelations. This inverse relationship is significant in daily returns but, with one exception, it does not carry over to the weekly returns. The study recommended that substantial portion of remaining nonlinearity in the conditional mean of all stock index returns examined can be attributed to positive feedback trading strategies.

Campbell, Grossman, \& Wang (1993) investigated the relationship between aggregate stock market trading volume and the serial correlation of daily stock returns. They found that the first-order daily return autocorrelation tends to decline with volume. Also, their study found that risk-averse "market makers" accommodate buying or selling pressure from "liquidity" or "non informational" traders. The study concluded that a stock price decline on a high-volume day is more likely than a stock price decline on a low-volume day to be associated with an increase in the expected stock return.

Andersen, Bollerslev, Diebold, \& Ebens (2000) exploit direct model-free measures of daily equity return volatility and correlation in the Dow Jones Industrial. They found that the unconditional distributions of the variances and covariances are leptokurtic and highly skewed to the right, while the logarithmic standard deviations and correlations all appear approximately Gaussian. They concluded that Positive returns have less impact on future variances and correlations than negative returns of the same absolute magnitude. Whereas, Bianco, Corsi, \& Ren`o (2008) confirmed the presence of LeBaron effect at intraday level complementing the efficient market hypothesis (for returns) with the heterogeneous market hypothesis (for volatility). They tested for the impact of unexpected volatility, defined as that part of volatility that cannot be forecast due to the presence of serial correlations in the time series. They found that contemporaneous volatility is significantly and positively correlated with the variance ratio. The study concluded that serial correlation is positively correlated with unexpected volatility, which is a previously unrecognized stylized fact of financial returns. The study recommended that the usual explanation of the LeBaron effect in terms of feedback trading is at least incomplete, advocating for a broader theory on the link between volatility and the way information is spread to heterogeneous market components.

Furthermore, David \& Simonovska (2015) investigated whether correlated beliefs among sophisticated, but imperfectly informed traders can account for the patterns of return correlations across countries. They made use of calibrated information-based model to establish the correlation of beliefs. The study found that market-wide volatility explained the cross-section of aggregate volatility. The results are robust to controlling 
for a number of alternative factors put forth by the existing literature. In furtherance of the significance of information in stock-return volatility, Balibey \& Turkyilmaz (2014) examined the convenience of the FIGARCH $(1, \mathrm{~d}, 1)$ and FIAPARCH $(1, \mathrm{~d}, 1)$ models in evaluating asymmetry features and long memory in the volatility of the Turkish Stock Market. The study confirmed that the FIAPARCH $(1, d, 1)$ model with skewed student-t distribution is more accurate for in-sample and out of- sample Value-at-Risk (VaR) analysis for short and long trading positions. In addition, the FIAPARCH (1, d, 1) model with skewed student-t has better accuracy results in capturing stylized facts in the volatility of Turkish Stock Market. The study concluded that evaluating of asymmetry and long memory property in volatility of the returns can ensure suitable Value-at-Risk $(\mathrm{VaR})$ model selection for performance of risk management in the Turkish financial markets. The study therefore recommended that the findings can be used by portfolio managers, investors, regulators and financial risk managers in decision making.

Günay (2014) examined the long memory property of conditional variance considering the existence of structural breaks in the series. Empirical analysis was conducted through FIGARCH, HYGARCH, GPH and modified GPH method of Phillips. The sequential method of Bai-Perron multiple structural breaks analysis indicated 3 and 4 breaks for the BIST100 and the BOVESPA indexes, respectively. The study found that conditional variance of both indexes have long memory property, that is, both indexes' volatilities are foreseeable under the past price information. The study concluded that there is presence of information conflicts with the weak form of the Efficient Market Hypothesis.

Hongngoc (2014) investigated the long memory returns for ETF (Emerging Markets Equities) returns index of seven Asian countries during 2008-2013 periods. The ARFIMA, ARFIMA-FIGARCH and ARFIMA-HYGARCH models were estimated. The empirical results of log-likelihood information criterion analyses the statistics that support ARFIMA-HYGARCH model instead of ARFIMA and ARFIMAFIGARCH model. The study found that the maximum values of log-likelihood of six series felt in estimations of ARFIMA-HYGARCH model. The study concluded that ARFIMA-HYGARCH model performs better than ARFIMA-FIGARCH and AFIMA models. However, Mohammadi \& Rezakhah, (2017) adopted Smooth Transition HYGARCH Model to analyze the time-varying structure with short and long memory property. The study found that ST-HYGARCH models outperform the HYGARCH model in forecasting. The study concluded that ST-HYGARCH models better forecast the true conditional variances than HYGARCH and the ST-HYGARCH (3) model have lower errors than to other models.

Watanabe (2002) examined the pattern of autocorrelation of daily stock index returns in the Tokyo Stock Exchange (TSE) by estimating the two variants of the EGARCH model by Nelson (1991). The study confirmed that stock returns exhibit positive autocorrelation when volatility is low but they exhibit negative autocorrelation when volatility is rather high and that stock returns are more negatively autocorrelated after price declines than after price rises. The study concluded that an increase in margin requirements makes stock returns more positively autocorrelated.

On a final note, Bollerslev, Osterrieder, Sizova \& Tauchen (2013) provided a detailed characterization of the dynamic dependencies and interrelatedness in aggregate stock market returns and volatilities using fractionally integrated processes. The study found that the coherence between volatility and the volatility risk reward is the strongest at long-run frequencies. Our results are consistent with generalized long-run risk models and help explain why classical efforts of establishing a naive return-volatility relation 
failed. The study concluded that high-frequency-based multivariate model implies nontrivial return predictability over longer monthly horizons.

\section{METHODOLOGY}

The central focus of this study is to examine the short run and long run linear dependencies of return and volatility in Nigerian stock market. To achieve these, we propose the so called ARMA-GARCH and ARFIMA-HYGARCH models. Specifically we follow the approaches of Davidson (2004) and Zhou, Chen \& Dong (2012). First we specify the ARMA and ARFIMA model.

\section{The ARMA and ARFIMA specifications}

The ARMA model provides the framework for examining short memory in return. It can be defined in terms of return on stock market as:

$r_{t}=a_{1} r_{t-1}+,,,+a_{p} r_{t-p}+e_{t}+b_{1} e_{t-1}+,,,+b_{q} e_{t-q}$

Equation 3.1 is ARMA (p, q) model, which can be transformed by introducing backshift (B) into it to have a more compacted definition.

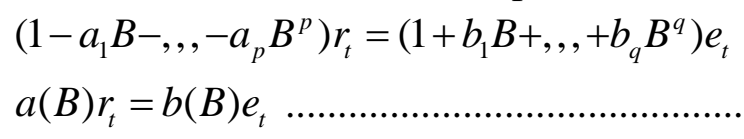

If the AR polynomial lies outside the unit cycle that is $a(B)=1-\sum_{i=1}^{p} a_{i} B^{i}<1$, which means the sum of all AR roots is less than unity, and the MA polynomial lies outside the unit cycle that is $b(B)=1+\sum_{j=1}^{q} b_{i} B^{i}<1$, which means the sum of all MA roots is less than unity, the ARMA will useful for studying the short memory characteristic of return. However, if $a(B)=1-\sum_{i=1}^{p} a_{i} B^{i}=1$ and $b(B)=1+\sum_{j=1}^{q} b_{i} B^{i}=1$, the appropriate specification is referred to $\operatorname{ARIMA~(p,d,~q),~where~} p$ is the lag length of the AR term, $d$ is the differenced or integrated order and $q$ is the lag length of the MA term. Thus, the first differenced ARIMA (p, 1, q) can be defined as:

$$
r_{t}=\ln p_{t}-\ln p_{t-1}
$$

3.4

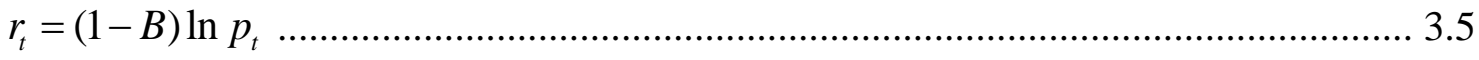

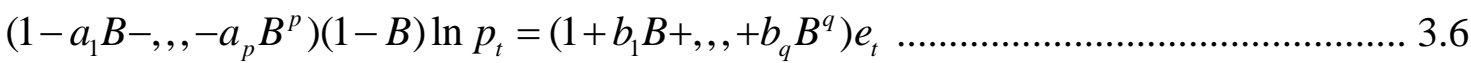

Equation 3.6 is not different from equation 3.2, but we can have a different equation if we move to second difference:

$$
\begin{aligned}
& r_{t}=(1-B)^{2} \ln p_{t} \ldots \ldots \ldots \ldots \ldots \ldots \ldots \ldots \ldots \ldots \ldots \ldots \ldots \ldots \ldots \ldots \ldots \ldots \ldots \ldots \ldots \ldots \ldots \ldots \ldots \\
& \left(1-a_{1} B-,,,-a_{p} B^{p}\right)(1-B)^{2} i n_{t}=\left(1+b_{1} B+,,+b_{q} B^{q}\right) e_{t}
\end{aligned}
$$

This may continue provided the system is not stationary. On this basis we can specify integrated order as:

$$
\left(1-a_{1} B-,,,-a_{p} B^{p}\right)(1-B)^{d} \ln p_{t}=\left(1+b_{1} B+,,,+b_{q} B^{q}\right) e_{t}
$$

If $\mathrm{d}$ is equal to 1 , then equation 3.9 is reduced to 6 or 3 , and the short run dependency can be examined. However, if $\mathrm{d}$ is less than 1, we have Autoregressive Fractionally Integrated Moving Average (ARFIMA) of order p, m, q, where $\mathrm{m}=1+\mathrm{d}$.

$$
\left(1-a_{1} B-,,,-a_{p} B^{p}\right)(1-B)^{1+d} \ln p_{t}=\left(1+b_{1} B+,,,+b_{q} B^{q}\right) e_{t}
$$




$$
\begin{aligned}
& \left(1-a_{1} B-,,,-a_{p} B^{p}\right)(1-B)(1-B)^{d} \ln p_{t}=\left(1+b_{1} B+,,,+b_{q} B^{q}\right) e_{t} \\
& \left(1-a_{1} B-,,,-a_{p} B^{p}\right)(1-B) \ln p_{t}=\frac{\left(1-b_{1} B-,,,-b_{q} B^{q}\right) e_{t}}{(1-B)^{d}}
\end{aligned}
$$

The fractionally differencing operator $(1-B)^{d}$ can be defined as.

$$
(1-B)^{d}=1-d B+\frac{d(d-1) B^{2}}{2}+\frac{d(d-1)(d-2) B^{3}}{3 \times 2}+\frac{d(d-1)(d-2)(d-3) B^{4}}{4 !}+\ldots \ldots . .
$$

Using hyper geometric function equation 3.13 can be represented as:

$$
(1-B)^{d}=\sum_{k=0}^{\infty}-(1)^{k} \frac{\chi(d-1)}{\chi(k+1) \chi(d-k+1)} B^{k}
$$

Once $\mathrm{d}$ is determined, $-(1)^{k} \frac{\chi(d-1)}{\chi(k+1) \chi(d-k+1)}$ can be expressed as a function of $\mathrm{k}[\mathrm{h}$ $(\mathrm{k})]$, therefore $(1-B)^{d}=\sum_{k=0}^{\infty} h(k) B^{k}$. This can be determined by fractionally integrating (fi) the $e=\left(e_{1}, \ldots, e_{t-q}\right)$ series. Then the series would yield $f i=\left(f i_{t}, \ldots, f i_{t-q}\right)$ series to have a well-simplified expression as:

$r_{t}=a_{1} B r_{t}+,,,+a_{p} B^{p} r_{t}+f i_{t}^{-1} e_{t}^{2}+\ldots+b_{q} f i_{t-q}{ }^{-1} e_{t-q}^{2}$

Equation 3.15 is referred to ARFIMA (p, d, q), where $d=1-m, m$ is expressed in fraction or percentage. And this can be used to study the long memory or long range linear dependency in return. We can now present the GARCH and HYGARCH models, which are required to examine short memory and long memory in volatility respectively.

\section{The GARCH and HYGARCH specifications}

The ARMA error in equation 3.2 is assumed to follow GWN process, which is defined as:

$e_{t}=z_{t} \sqrt{h}$

$e_{t} \sim G W N\left(0, \sigma^{2}\right) ; z_{t} \sim G W N\left(0, \sigma^{2}\right) ; h_{t}>0$. According to Bollerslev (1986) and in line with these assumptions the standard GARCH model is written as:

$h_{t}=c_{0}+c_{1} e_{t-1}^{2}+\ldots+c_{q} e_{t-q}^{2}+\theta_{1} h_{t-1}+\ldots+\theta_{1} h_{t-p \theta}$

Equation 3.17 describes GARCH (q, p) model, which explains the short run dependency in volatility of return. This equation can be rewritten as:

$\theta(B) h_{t}=c_{0}+c(B) e_{t}^{2}$

$c(B) e_{t}^{2}=(1+\lambda B) e_{t}^{2}$

$h_{t}=\frac{c_{0}}{\theta(1)}+\left(1+\frac{\lambda B}{\theta(B)}\right) e_{t}^{2}$

3.20

The integrated GARCH model can be specified by introducing 1-B into equation 3.20 to have

$h_{t}=\frac{c_{0}}{\theta(1)}+\left(1+\frac{\lambda B(1-B)}{\theta(B)}\right) e_{t}^{2}$

If the GARCH error is integrated d times, the expression 3.21 can be restated as: 
$h_{t}=\frac{c_{0}}{\theta(1)}+\left(1+\frac{\lambda B(1-B)^{d}}{\theta(B)}\right) e_{t}^{2}$

Equation 3.22 is referred to as Fractionally Integrated GARCH (FIGARCH) model introduced by Baillie, Bollerslev \& Mikkeslen (1996). The model has two components the amplitude $(S)$ and fractionally differencing $(1-B)^{d}$. Baillie et al (1996) defined $S=\lambda(1)=1$. This indicates that FIGARCH is not covariance stationary because $S=1$. This may contradicts the assumption that the length of the memory increases as d increases (Davidson, 2004). Another shortcoming of FIGARCH is that it has infinite variance. To overcome these weaknesses, Davidson (2004) proposed Hyperbolic GARCH (HYGARCH) specification, which assumes that $S<1$, by introducing another parameter $\varphi$ into the lag polynomial, HYGARCH expressed as:

$h_{t}=\frac{c_{0}}{\theta(1)}+\left(1+\frac{\lambda B\left[1+\varphi(1-B)^{d}-1\right]}{\theta(B)}\right) e_{t}^{2}$

$\lambda=1-c$

$s=1-\frac{c}{\theta}(1-\varphi)<1$

Equation 3.25 shows that the length of the memory increases as the $\mathrm{d}$ increases. So, HYGARCH is a generalization of the FIGARCH model. It is adopted in this study to examine the long run dependency in volatility of return.

\section{RESULTS AND DISCUSSIONS}

Data on all share index from Nigerian Stock Exchange (NSE) were collected on daily basis over the period 2000 to 2016 . The preliminary tests conducted on these data indicate the features of the index. Table 1 presents the results of normality test.

Table 1.Normality test results

\begin{tabular}{lccc}
\hline Stat & Value & T-value & P-value \\
\hline Skewness & 0.61734 & 16.273 & $1.5394 \mathrm{e}-059$ \\
Excess Kurtosis & 23.739 & 312.95 & 0.0000 \\
Jarque-Bera & 98086 & $\mathrm{NA}$ & 0.0000 \\
Lilliefors (D) & 0.092636 & $\mathrm{NA}$ & 0.0000 \\
Cramer-von Mises & 16.52897 & 16.53095 & 0.0000 \\
Watson (U2) & 16.49779 & 16.49977 & 0.0000 \\
Anderson-Darling & 93.81322 & 93.83012 & 0.0000 \\
Mean & 0.0004375 & 10.67264 & 0.0000 \\
\hline
\end{tabular}

Source: Authors' Computation

In Table 1, the mean or average value of stock market return is 0.00044 and significantly different from zero and negative, implying a very low average value. The preposition of normality is rejected by Jarque-Bera, Lilliefors, Cramer-von Mises, Watson and Anderson-Darling tests. The excess kurtosis is positive and significant, giving evidence of peakness or leptokurtic distribution. The coefficient of skewness is approximately one or greater than zero. This means the Nigerian stock market return is asymmetric and follows a nonlinear historical pattern. For purpose of iteration, the nonlinearity and leptokurtic tendencies are demonstrated in Figures 1 and 2 (Appendix) respectively

Figure 1shows that the distribution of Nigerian stock market return is peaked. This indicates presence of outlier, asymmetry, and high expectation of future values. 
The scatter plot, in Figure 2, is not a replica of a steady ellipsoid; this confirms the asymmetric process of stock market return evolution. The reversibility of the logarithmic and differenced series of the index is examined using unit root tests based on Augmented Dickey-Fuller, Phillip-Perron, and Kwiatkowski-Phillips-Schmidt-Shin. For confirmation see Table 2 for the results of unit root tests.

Table 2. Unit root test

\begin{tabular}{lcc}
\hline Test & log of market index & Return on Market \\
\hline ADF & $-1.838134(-3.410884)$ & $-35.61496(-2.862038)$ \\
PP & $-1.765351(-3.410884)$ & $-47.59493(-2.862037)$ \\
KPSS & $1.22695(0.146000)$ & $0.097132(0.146000)$ \\
\hline
\end{tabular}

Note the values in the parentheses are the $5 \%$ critical value

Source: Authors' Computation

The test results in Table 2 revealed to us that the ADF and PP statistics appear smaller than the 5\% critical value for the logarithmic series, but the statistics are greater in respect of the differenced series. The KPSS statistics are greater than the $5 \%$ critical value with the logarithmic series but smaller in term of the differenced series. Thus, the logarithmic stock index series is characterized with unit root and must be differenced. Further justification of this is demonstrated in Figures 3 and 4 (Appendix) respectively for the line graphs of logarithmic and differenced series.

Figure 3 shows clearly a random walk process for greater parts of the distribution, while a reversible process is mostly represented in Figure 4. This suggests that stock return is mean reverting but raw prices are not. We now check if the variance of return is conditioned on time as shown in Figure 5 below:

Figure 5 (Appendix) reveals that conditional variance is not constant (that is 1) but varies significantly with time, in which case there are low and high variancesheterogeneous variance over range of time. To corroborate this, we conduct ARCH effects test at different lags. Table 3 reports the ARCH effects test.

Table 3. ARCH effects test

\begin{tabular}{lcc}
\hline Test & Value & Probability \\
\hline ARCH (2) & 677.46 & {$[0.0000]$} \\
ARCH (5) & 303.40 & {$[0.0000]$} \\
ARCH (10) & 151.83 & {$[0.0000]$} \\
\hline
\end{tabular}

Source: Authors' Computation

It is really obvious in Table 3 that the series of return exhibits ARCH effects at lags 2, 5, and 10 respectively. The evidence of conditional heteroscedasticity demonstrated in Figure 5 is very resilient. We consider again if daily stock market returns are linearly dependent or nonlinearly dependent using BDS test. The result is displayed in Table 4.

Table 4. BDS test result

\begin{tabular}{llccc}
\hline Dimension & BDS-Stat & Std-Error & Z-Stat & P-value \\
\hline 2 & 0.054019 & 0.001556 & 34.71724 & 0.0000 \\
3 & 0.091643 & 0.002471 & 37.08066 & 0.0000 \\
4 & 0.114047 & 0.002942 & 38.76267 & 0.0000 \\
5 & 0.123698 & 0.003066 & 40.34446 & 0.0000 \\
6 & 0.124560 & 0.002957 & 42.12998 & 0.0000 \\
\hline
\end{tabular}

Source: Authors' computation 
The BDS (Brook, Dechert \& Scheinkman, 1987) test in Table 4 shows asymptotic $\mathrm{Z}$ statistics at every dimension ( 2 to 6 ) with zero probability. This confirms the presence of nonlinear dependency characterizing the daily stock market return in Nigeria. Though the BDS test has established short run autocorrelation, yet it is economically impossible for chartists to exploit this opportunity to make abnormal return in the short run (Chikhi, Peguin-Feissolle \&Terraza, 2013). Hence, it is economically (but not statistically) wise to reject the hypothesis of autocorrelation. However, long run permits valid prediction because of wide dynamics of the horizon. Emphatically, we conduct a pre-test of long run cyclical tendency of return structure using Hurst-Mandelbrot and Lo rescale $(\mathrm{R} / \mathrm{S})$ test. The statistics at three distict levels of confidence are reported in Table 5 .

Table 5. Hurst-Mandelbrot and Lo R/S Test

\begin{tabular}{lcccc}
\hline Test & Value & C-Value & C-ValueC-Value & \\
& & @90\% & $@ 95 \%$ & $@ 99 \%$ \\
\hline Hurst-Mandelbrot & 2.4786 & {$[0.861,1.747]$} & {$[0.809,1.862]$} & {$[0.721,2.098]$} \\
Lo & 2.1745 & {$[0.861,1.747]$} & {$[0.809,1.862]$} & {$[0.721,2.098]$} \\
\hline
\end{tabular}

Source: Authors' Computation

Both Hurst-Mandelbrot and Lo statistics are statistically significant. This leads to the rejection of no autocorrelation and long term structural dependence. We further confirm this by plotting the periodograms of return and volatility of return shown in Figures 6 and 7 (Appendix) respectively.

A thorough sight view of Figures 6 and 7 indicates that the spectral density of return and volatility concentrate on low frequencies, and as the frequency tends towards zero, the density tends progressively to perpetuity. This is an approximated sign for long run autocorrelation. We verified this by exploring nonlinear models specifically, ARFIMA, GARCH, FIGARCH and HYGARCH. We first report the results of ARMAARFIMA in Table 6.

Table 6. ARMA-ARFIMA estimation results

\begin{tabular}{lcc}
\hline Parameter & ARMA & ARFIMA \\
\hline $\mathrm{a}$ & $0.010000(0.8795)$ & $0.010000(0.9659)$ \\
$\mathrm{b}$ & $0.010000(0.8831)$ & $0.010000(0.9666)$ \\
$\mathrm{d}$ & - & $0.100000(0.0000)$ \\
\hline
\end{tabular}

Note: the results in Table 6 are estimated from equations 3.2 and 3.15 respectively with lag length $p=1, q=1$; the figure in parentheses are the $p$-values.

Source: Authors' Computation

It is very clear in Table 6 that the ARMA parameters ( $a$ and $b$ ) are not significant, meaning that there is no significant ARMA structure characterizing the daily returns of Nigeria stock market. This implies that prediction of return is infeasible in the short run; speculators' goal is futile because stock market returns in the short run are not connected. However, the long run parameter (d) as revealed by the ARFIMA is significant at 1 percent. This result has reinforced the Lo's test in Table 5, earnestly suggesting that the stock market returns persist over long term range rather than short term range in Nigeria. By implication, our report shows that in the short term period, stock market return cannot be predicted; to the contrary, in the long run period return can be predicted in the Nigerian stock market. This means that our estimated results from the ARFIMA model do not complement the EMH, and thus, we have evidence 
dully supported by Booth \& Koutmos (1988) in European stock market. In addition, our evidence of long memory in return is in tandem with the findings of Watanaba (2002) in Tokyo Stock Exchange. To extend this investigation to volatility, GARCH, FIGARCH and HYGARCH are estimated and the results are shown in Table 7.

Table 7. GARCH-FIGARCH-HYGARCH estimation results

\begin{tabular}{lccc}
\hline Parameter & GARCH & FIGARCH & HYGARCH \\
\hline$\theta$ & $0.077586(0.0000)$ & $0.070594(0.0000)$ & $0.112699(0.0010)$ \\
$\lambda$ & $0.878862(0.0000)$ & $0.496672(0.0000)$ & $0.380862(0.0000)$ \\
$\mathrm{d}$ & - & $0.463569(0.0000)$ & $-0.370489(0.0000)$
\end{tabular}

Note: the results in Table 7 are estimated from equations 3.17, 3.22 and 3.23 respectively with lag length $p=1, q=1$; the figure in parentheses are the $p$-values Source: Authors' Computation

Going by the results in Table 7, we have documented significant GARCH (1 1) process. The FIGARCH and HYGARCH parameters (including the long run parameter) are also significant. Therefore, our results uphold the presence of both short run and long run cyclical structure in volatility. In very simple terms, there is autocorrelation of volatility in short run and long run horizons, which makes prediction of volatility possible in Nigerian stock market. This deters EMH, by claiming that investors can employ historical information about volatility to forecast future volatility. This, thus fall within the evidences documented by David \& Simonoysska (2015), Guinay (2014) and Balibey \& Turkyilmaz (2014) that support our findings on long run volatility interdependency. More-also, our claim of ARFIMA-HYGARCH evidence in Nigerian stock market is supported by the study of Hongngoc (2014) in seven Asian countries. We conduct batteries of tests to evaluate the forecasting strength on the candidate models based on loss functions. The results are summarized in Tables 8 and 9 .

Table 8. Forecasting strength of ARMA-ARFIMA

\begin{tabular}{lrr}
\hline Test & ARMA & ARFIMA \\
\hline Mean Squared Error (MSE) & 0.0002616 & 0.0001312 \\
Median Squared Error (MSE) & 0.0002033 & $8.622 \mathrm{e}-005$ \\
Mean Error (ME) & -0.01521 & -0.01002 \\
Mean Absolute Error (MAE) & 0.01521 & 0.01002 \\
Root Mean Squared Error (RMSE) & 0.01617 & 0.01145 \\
Theil Inequality Coefficient (TIC) & 0.921 & 0.9246 \\
\hline
\end{tabular}

\section{Source: Authors' Computation}

The loss function statistics are in favour of ARFIMA except in the case of TIC. In this regards we propose ARFIMA $(1,0.10,1)$ model as a better forecasting model than ARMA $(1,1)$ in Nigerian stock market. Let us see Figures 8, 9, 10 and 11 (Appendix) for additional explanation.

The conditional mean of shocks appears fairly constant and highly probably unvaried with time, truly white noised and random. Therefore, ARMA does not represent a good predictive model in Nigerian stock market. Clear distinctions between the ARMA and ARFIMA are that ARFIMA reveals connectivity between conditional mean of residual and return. Again the conditional mean is time bound. In this regards we suggest that ARFIMA must be a better predictive model compared to ARMA. 
Table 9. Forecasting Strength of GARCH-FIGARCH-HYGARCH

\begin{tabular}{lrrr}
\hline Test & \multicolumn{1}{c}{ GARCH } & \multicolumn{1}{c}{ FIGARCH } & \multicolumn{1}{c}{ HYGARCH } \\
\hline Mean Squared Error (MSE) & $2.668 \mathrm{e}-016$ & $5.638 \mathrm{e}-016$ & $5.236 \mathrm{e}-014$ \\
Median Squared Error (MSE) & $7.349 \mathrm{e}-017$ & $4.562 \mathrm{e}-016$ & $5.421 \mathrm{e}-014$ \\
Mean Error (ME) & $-3.674 \mathrm{e}-009$ & $-1.663 \mathrm{e}-008$ & $-2.266 \mathrm{e}-007$ \\
Mean Absolute Error (MAE) & $1.217 \mathrm{e}-008$ & $2.273 \mathrm{e}-008$ & $2.266 \mathrm{e}-007$ \\
Root Mean Squared Error (RMSE) & $1.633 \mathrm{e}-008$ & $2.374 \mathrm{e}-008$ & $2.288 \mathrm{e}-007$ \\
Theil Inequality Coefficient (TIC) & 0.3739 & 0.4183 & 0.8541 \\
\hline
\end{tabular}

Table 9 shows that FIGARCH is only selected by ME, while HYGARCH is favoured by all the tests except ME and TIC while GARCH is selected by TIC. HYGARCH has the most predictive power, and then followed by GARCH. FIGARCH lose out because of its weakness (see Davidson, 2004). The residuals and conditional variances of these models are presented in Figures 12, 13, 14, 15, 16 and 17 (Appendix).

Figure 12 provides an indication that shocks vary with time and Figure 13 shows that the conditional variance decays geometrically within the purview of a short run horizon. As shown in Figure 15, the FIGARCH conditional variance is the inverse of the GARCH conditional variance. Again it first decreases and increases with time, and disappears slowly on long time range. Figures 16 and 17 reveal that variance and shocks pool with tine on a long time range. It is practically overt that the conditional variance decays hyperbolically as shown in Figure 17.

\section{CONCLUSION AND RECOMMENDATIONS}

\section{Conclusion}

We proposed family of ARMA and GARCH specifications to investigate whether stock return and volatility in Nigerian stock market exhibit short/long range cyclical structure. The results revealed short run memory-less in return. Thus, we conclude that in the short run the market does not have memory in return, and the possibility of correctly predicting returns is extreme. However, long run memory in return was not refuted, this gives an indication that in the long run the Nigerian stock market is inefficient, speculative activities and riskless abnormal returns are sustained simultaneously. In addition, we found that volatility is auto-correlated both in the short and long-run periods. In this regard, we conclude that there are effects of shocks on volatility in all market cycles, and the shocks disappear in the short run rapidly, while in the long run they decay slowly. Based on these two results, we conclude that in Nigerian stock market, there is single memory in return, but double memory in volatility.

\section{Recommendation}

The supervisory unit in the Nigerian stock market should initiate a more robust platform through which information can easily be disseminated to all participants in the market. This can be archived by introducing a policy of increasing market competition or relaxation of listing requirements to accommodate more companies to be quoted and sustain optimal spread of information. Finally, among the competing models, we recommend ARFIMA and HYGARCH as the best alternative models for forecasting in the Nigerian stock market. 


\section{REFERENCES}

Andersen, T.G., Bollerslev, T. Diebold, F. X., \& Ebens, D. H. (2000). The distribution of stock return volatility. Journal of Financial Economics, 61, 43-76.

Baillie, R. T.,Bollerslev, B. T., \& Mikkeslen, H. O. (1996). Fractionally integrated generalized autoregressive conditional heteroscedasticity. Journal of Econometrics, 74, 13-30.

Balibey, M., \& Turkyilmaz, S. (2014). Value-at-Risk analysis in the presence of asymmetry and long memory: The case of Turkish stock market. International Journal of Economics and Financial Issues, 4(4), 836-848.

Bianco, S., Corsi, F., \& Ren`o, R., (2008). Serial correlation and heterogeneous volatility in financial markets: Beyond the LeBaron effect, Arxiv: 0810.491v1(qfin-ST).

Bollerslev, T. (1986).Generalized autoregressive conditional heteroscedasticity. Journal of Econometrics,31, 307-327.

Bollerslev, T., Osterrieder, D., Sizova, N., \& Tauchen, G. (2013). Risk and return: Long-run relations, fractional cointegration and return predictability. Journal of Financial Economics, 108, 409-424.

Booth, G. G., \& Koutmos, G. (1988).Volatility and autocorrelation in major European stock markets. European Journal of Finance, 4, 61-74.

Brock, W.A., Dechert, W.D., \& Scheinkman, J. (1987). A test for independence based on the correlation dimension. Discussion Paper 8702, University of WisconsinMadison.

Campbell J., Grossman, S. J., \& Wang, J. (1993). Trading volume and serial correlation in stock returns. Quarterly Journal of Economics, 108(4), 907-921.

Chikhi, M., Peguin-Feissolle, A., \& Terraza, M. (2013). SEMIFARMA-HYGARCH modelling of Dow Jones return persistence. Computational Economics, 41(2), 254-261.

Davidson,J. (2004). Moments and memory properties of linear conditional heteroscedasticity models and a new model. Journal of Business and Economic Statistics, 22, 16-29.

David, J.M., \& Simonovska, I. (2015).Correlated beliefs, returns, and stock market volatility.UC Davis, NBER.

Günay, S. (2014). Long memory property and structural breaks in volatility: Evidence from Turkey and Brazil. International Journal of Economics \& Finance, 6(12), 119-130.

Hongngoc, T. (2014). Arfima-Figarch vs .Arfima-Hygarch: Case study ETF returns of emerging Asian Countries. Asian Journal of Finance \& Accounting, 6 (2), 176192.

Mohammadi, F., \& Rezakhah, S. (2017). Smooth transition HYGARCH model: Stability and forecasting. Arxiv: 1701.05358v1 (Stat.CO).

Watanabe, T. (2002). Margin requirements, positive feedback trading, and stock return autocorrelations: The case of Japan. Applied Financial Economics, 12, 395-403.

Zhou, D., Chen, S., \& Dong, S. (2012). Network traffic prediction based on ARFIMA model. IJCSI International Journal of Computer Science Issues, 9(6), 106-111. 


\section{APPENDIX}

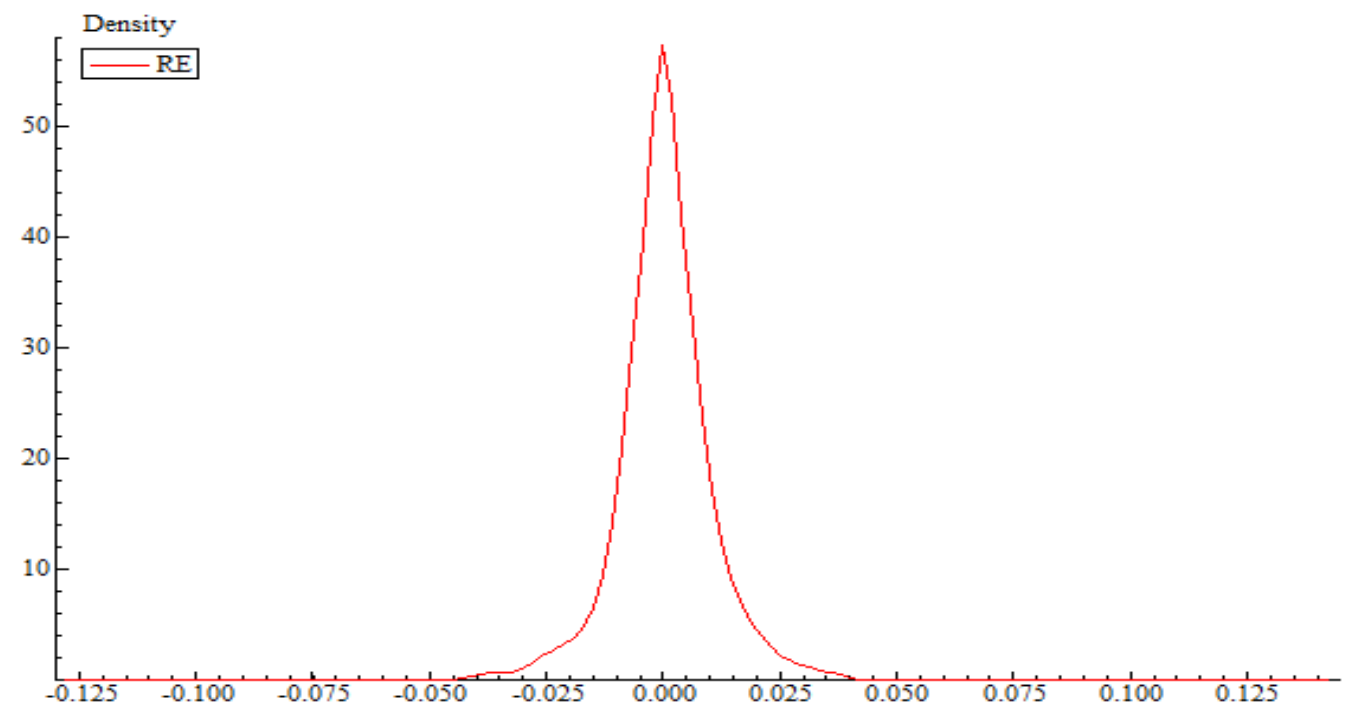

Figure 1. Density plot of market return

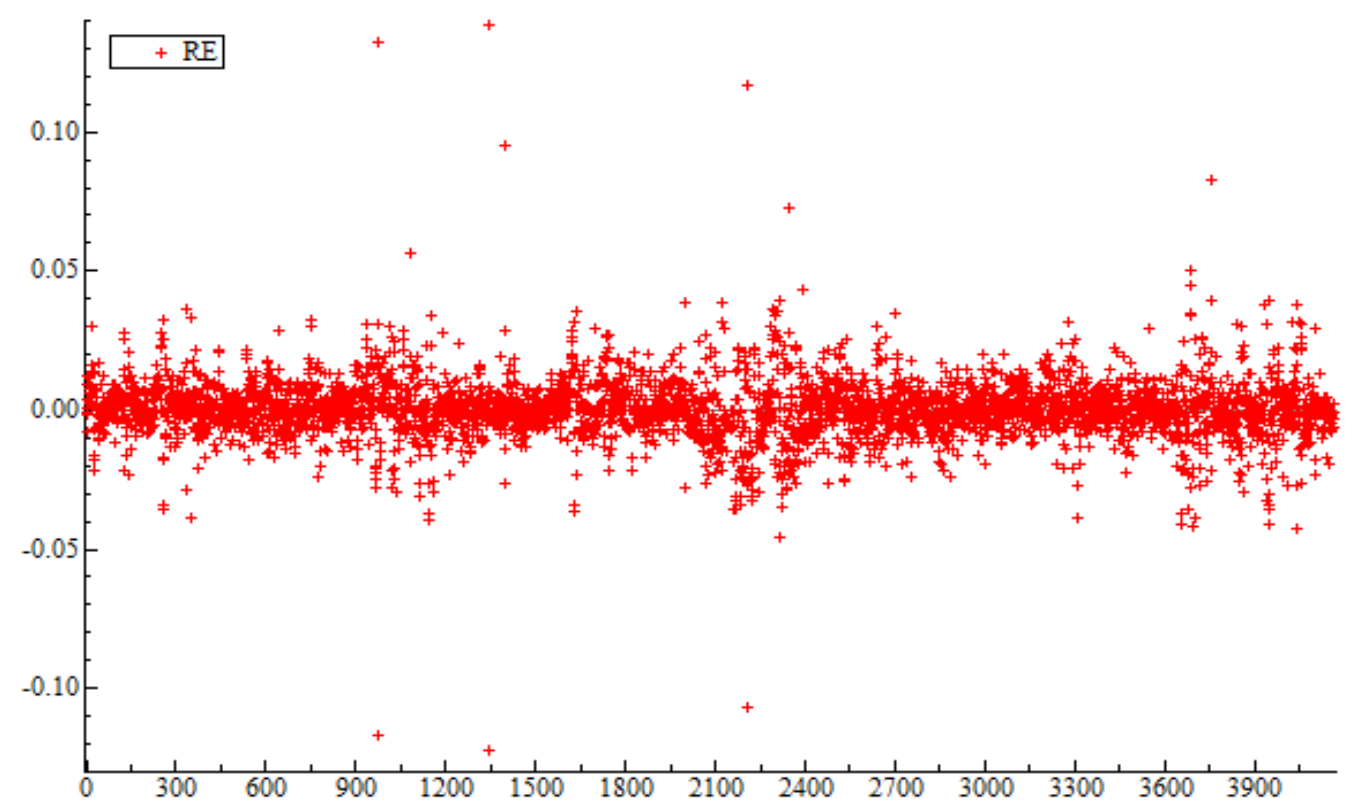

Figure 2. Scatter plot of market return 


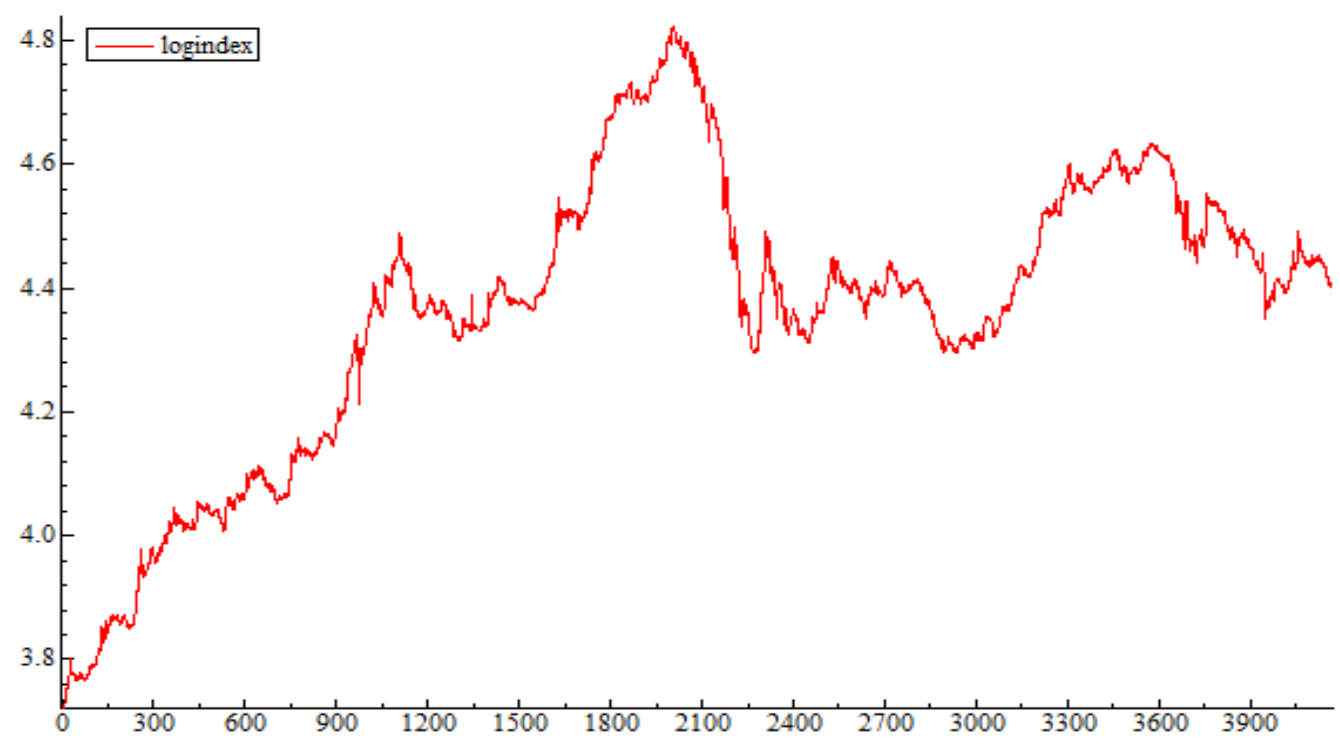

Figure 3.Line graph plot for log index

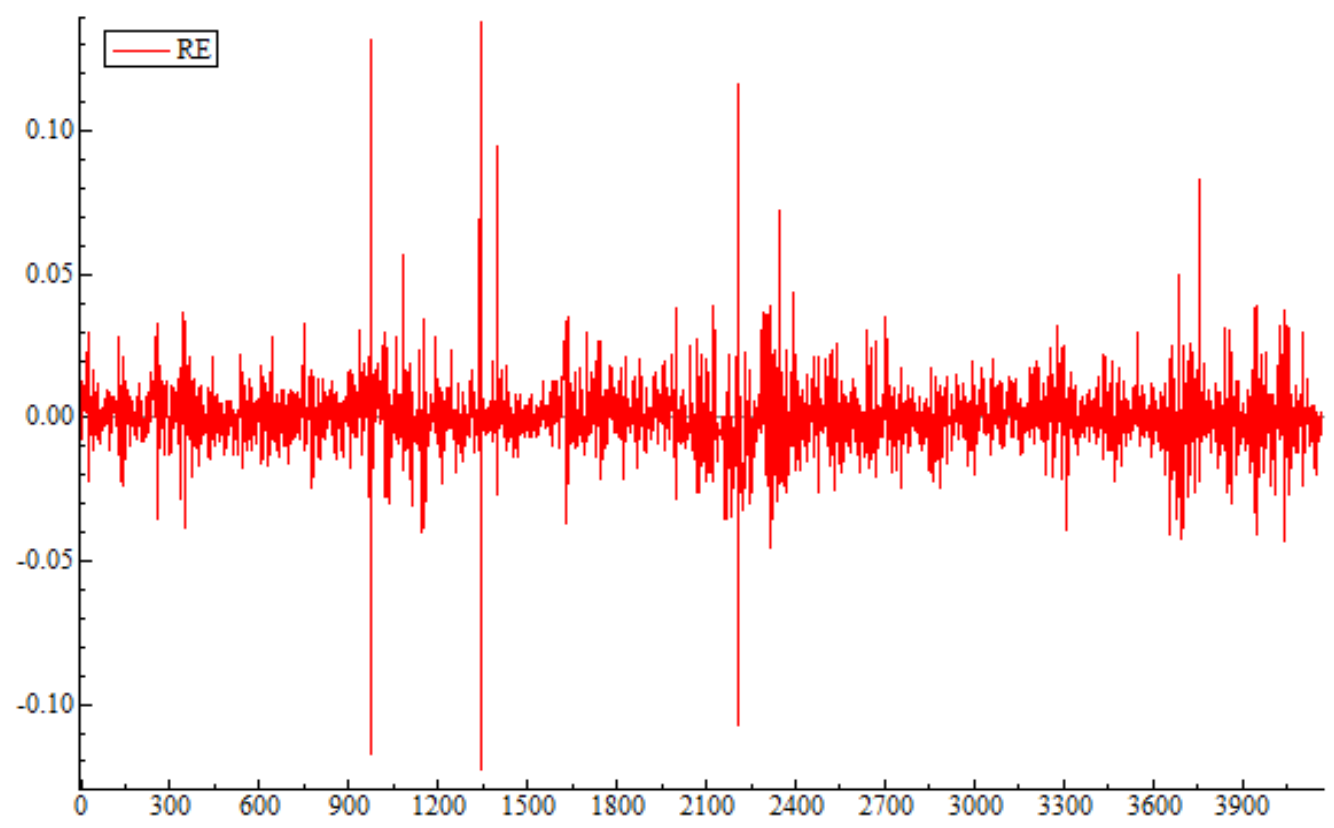

Figure 4. Line graph plot for differenced index 


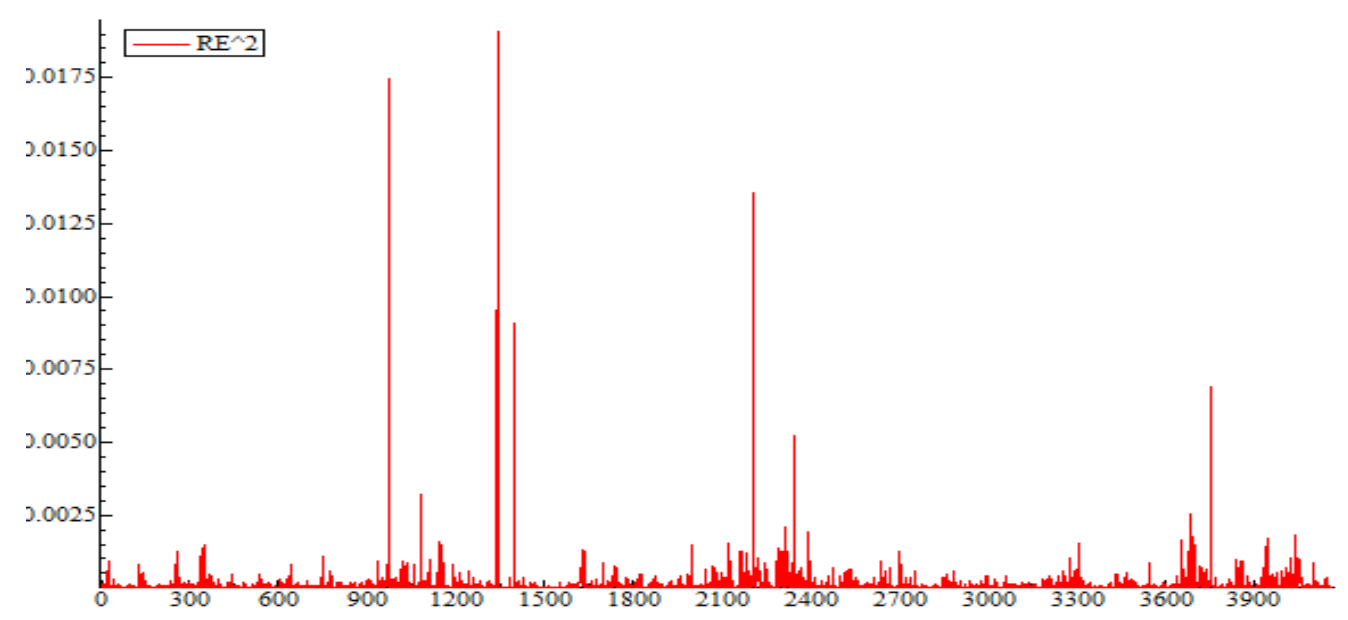

Figure 5. Conditional variance of return

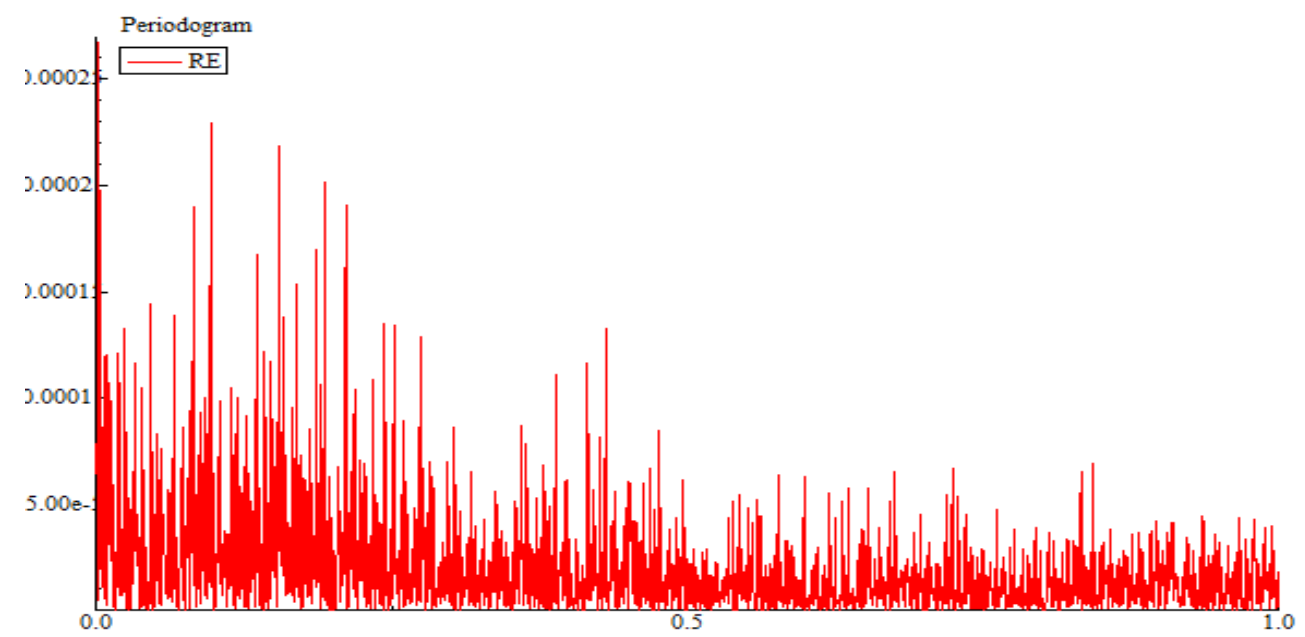

Figure 6. Periodogram of return

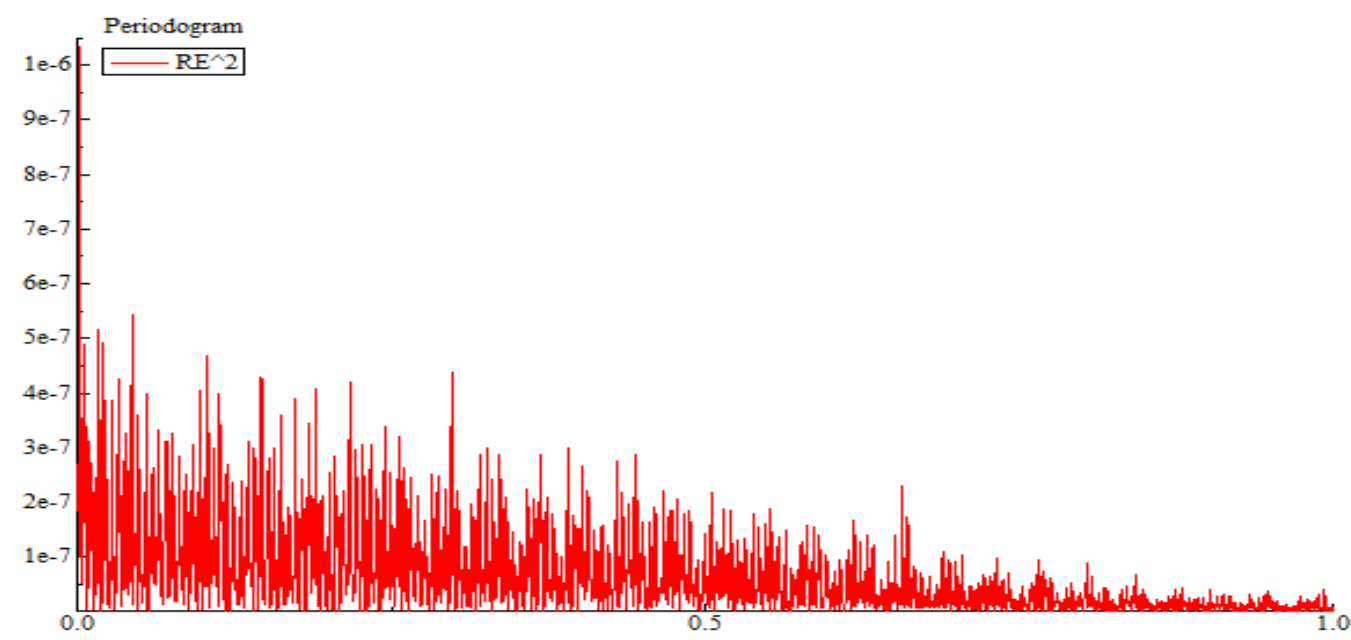

Figure 7. Periodogram of volatility 


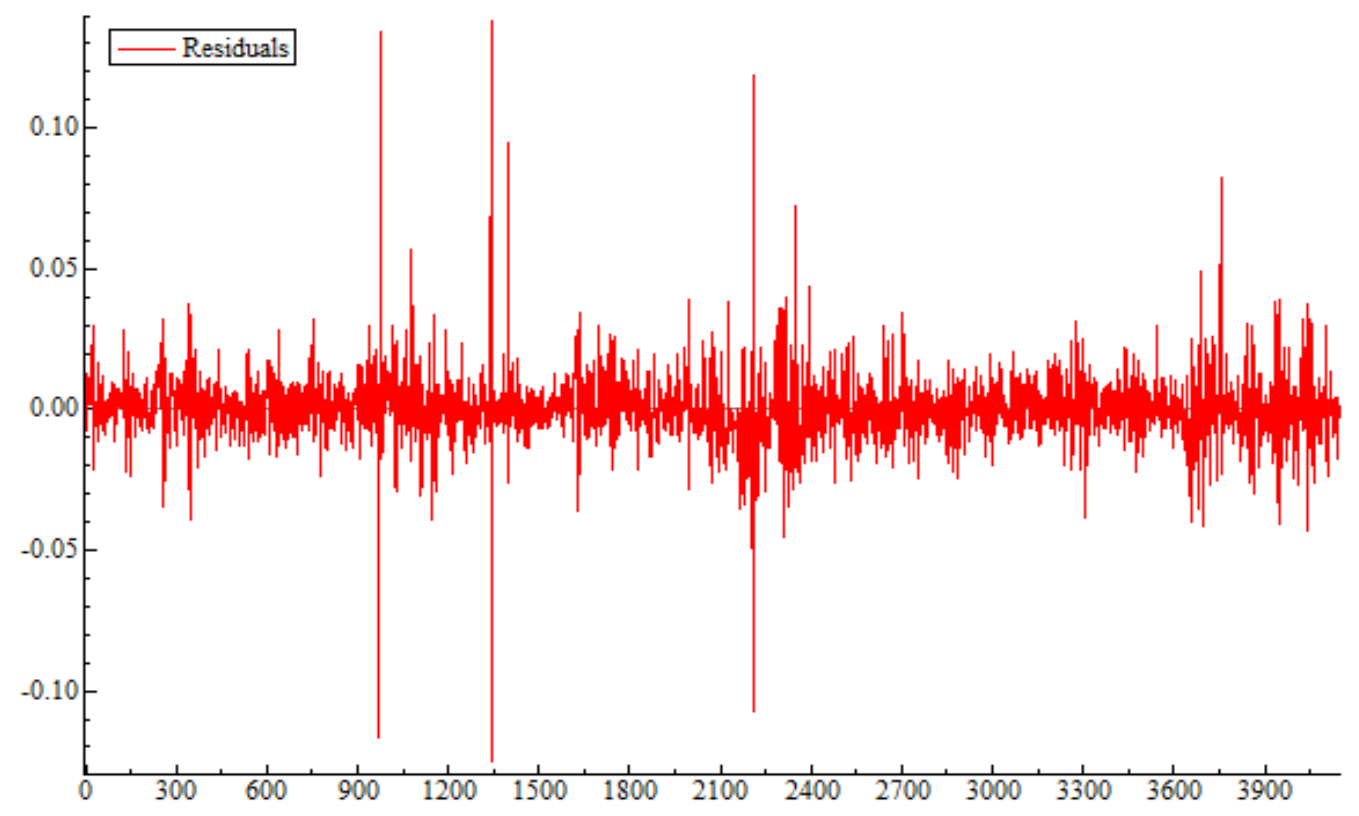

Figure 8. ARMA residual

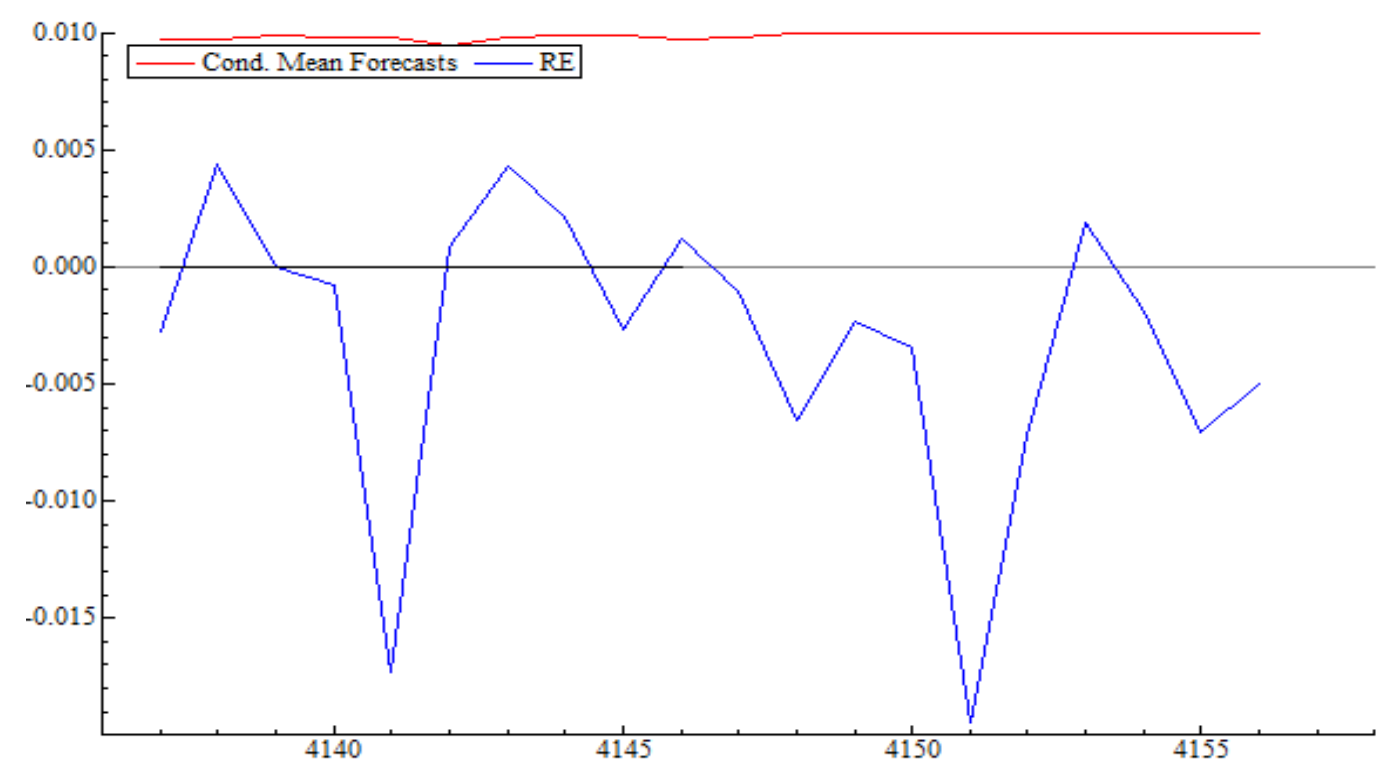

Figure 9. ARMA conditional mean 


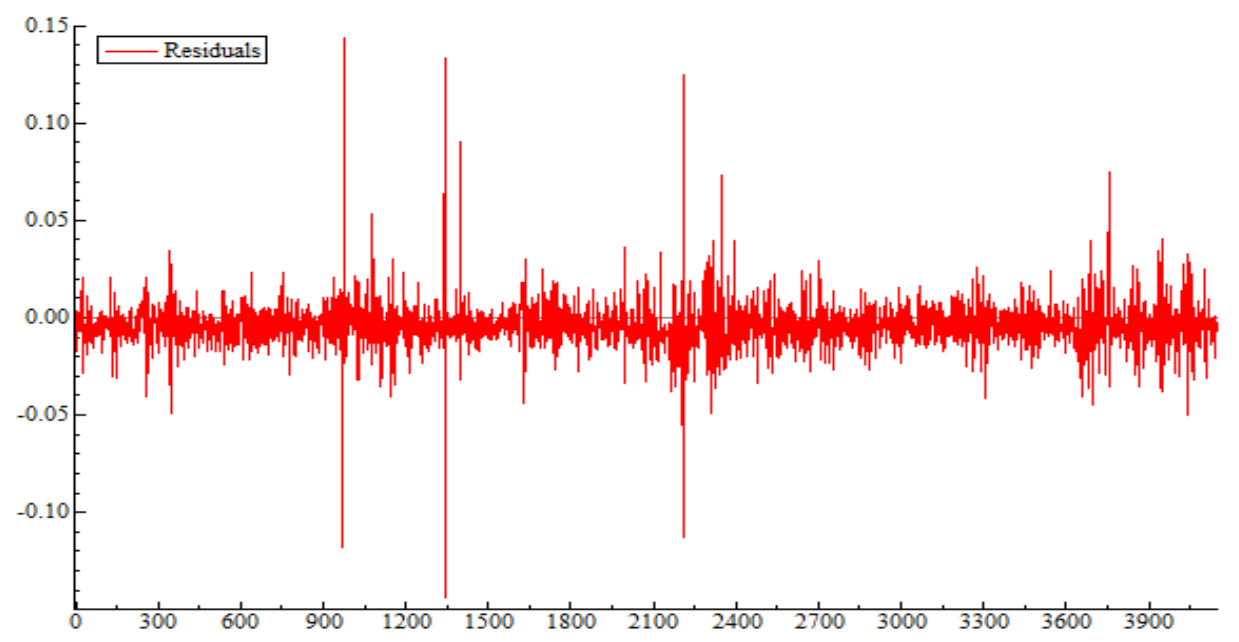

Figure 10. ARFIMA residual

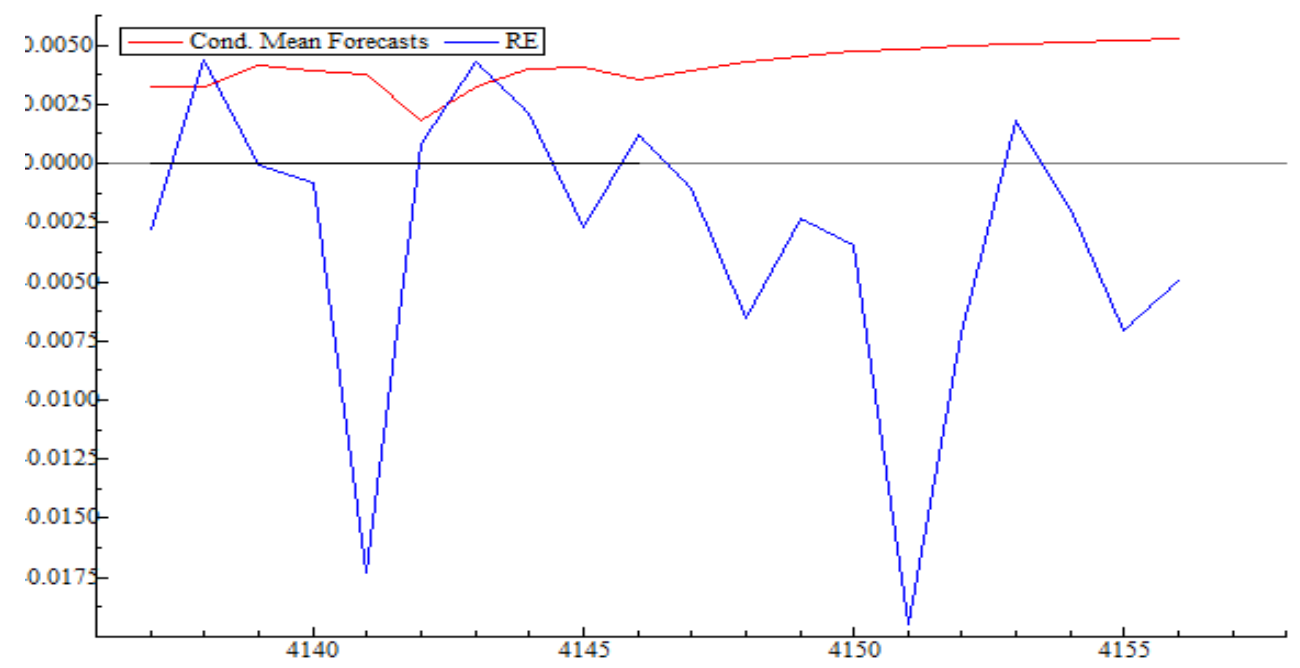

Figure 11. ARFIMA conditional mean

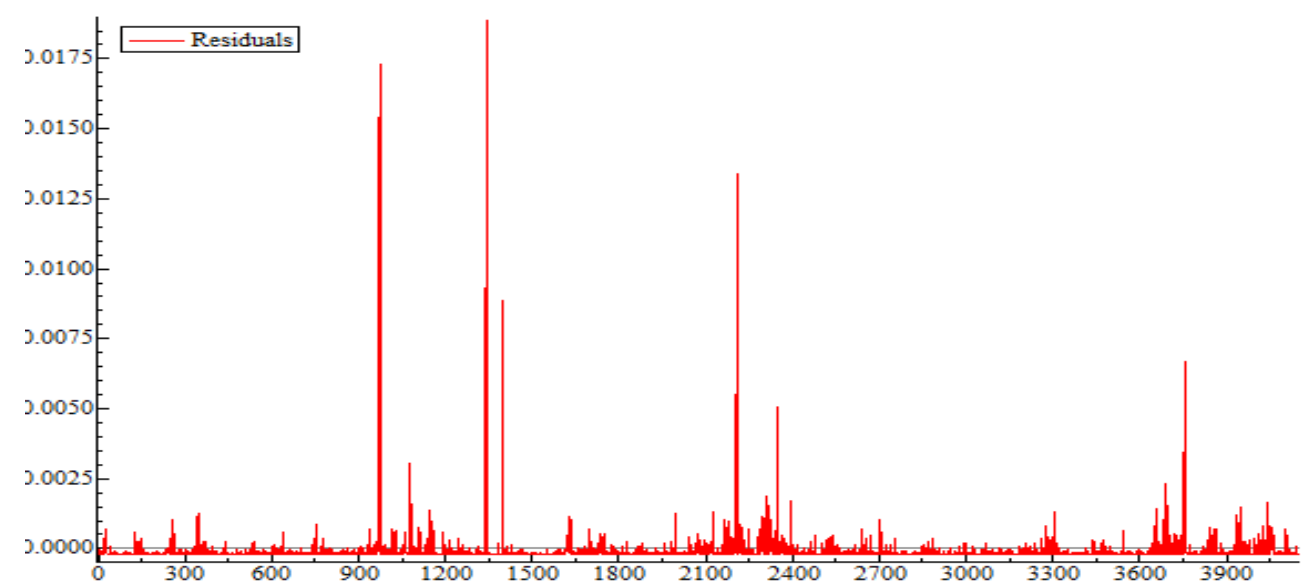

Figure 12. Residual of GARCH 


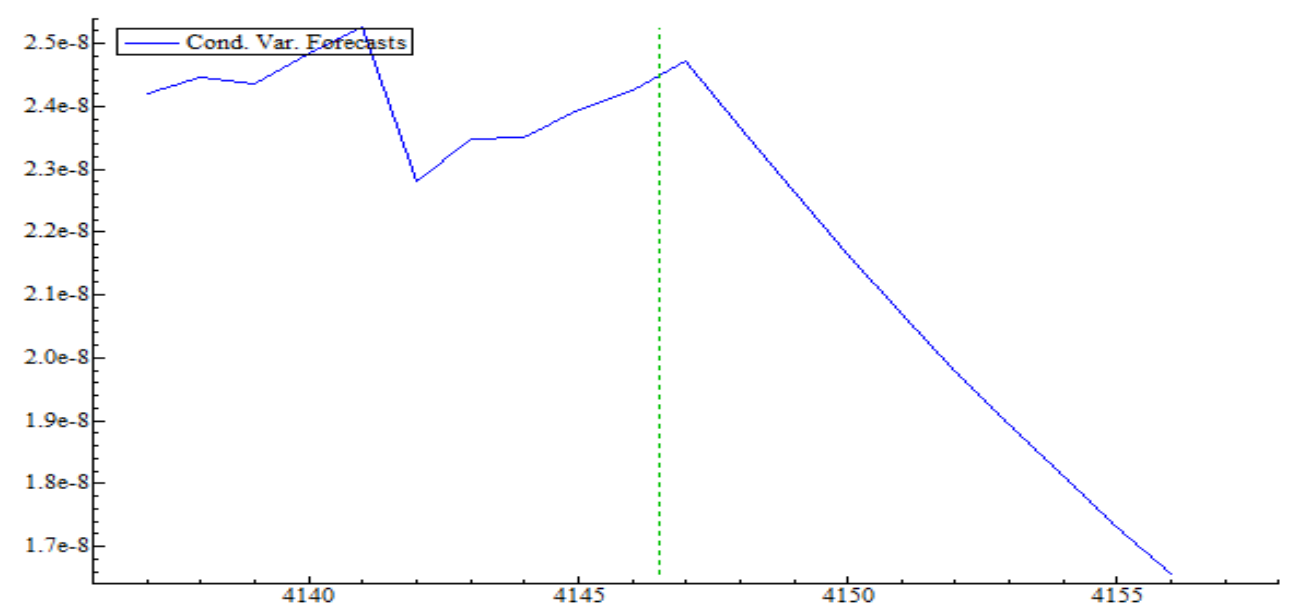

Figure 13. Conditional variance of GARCH

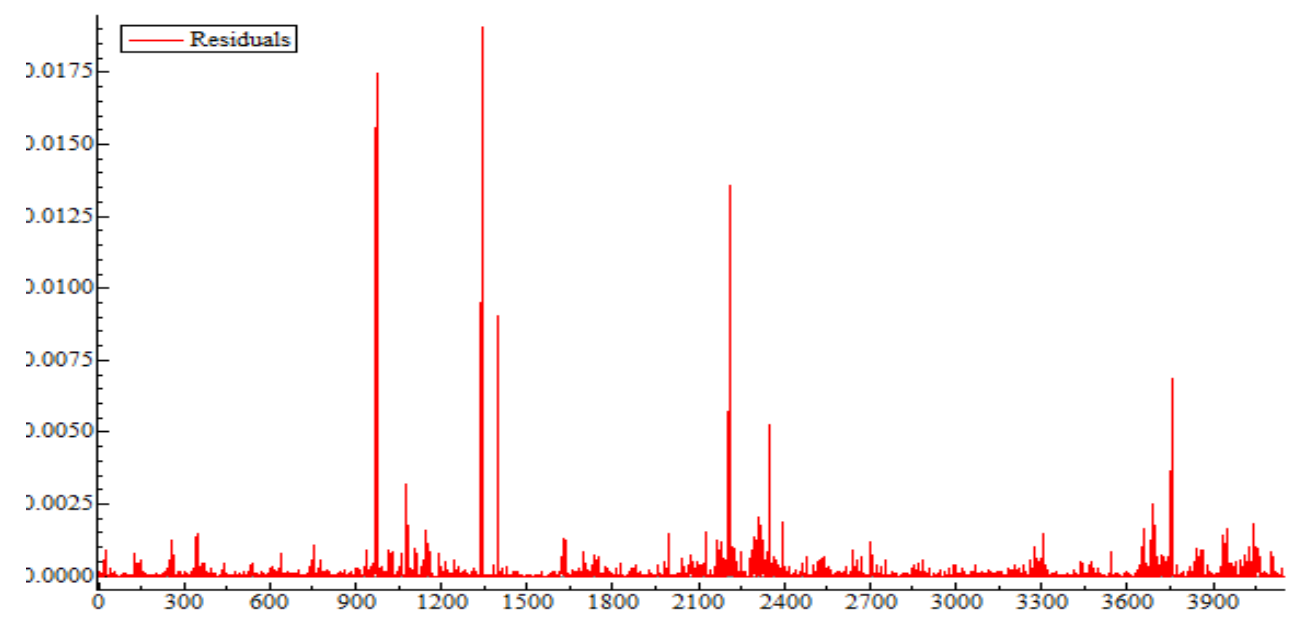

Figure 14. Residual of FIGARCH

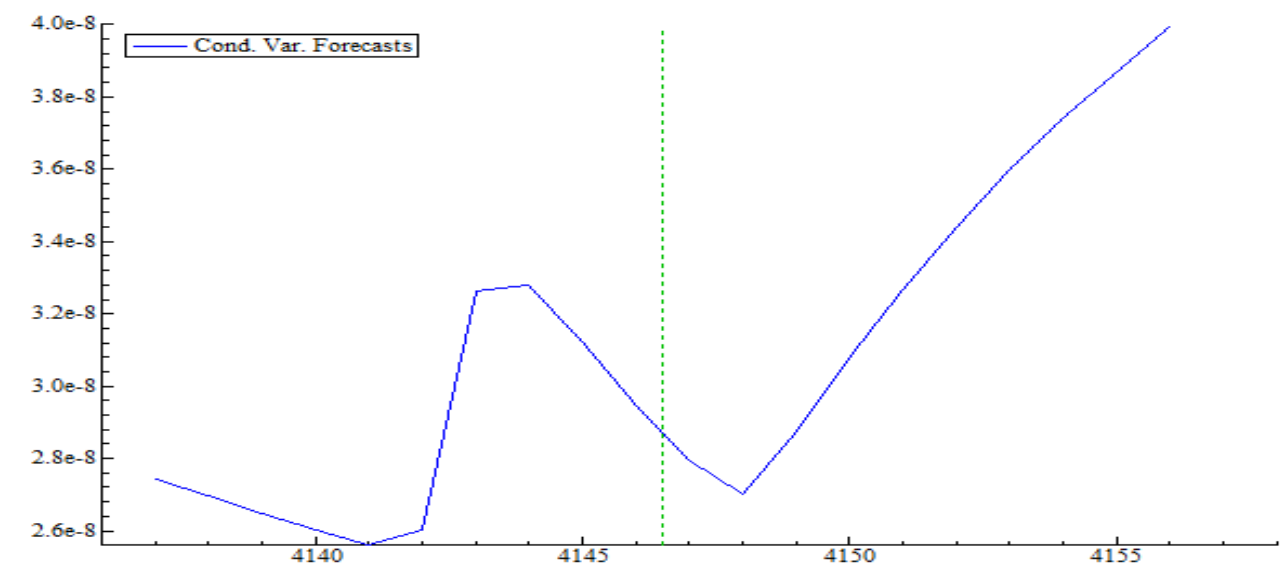

Figure 15. Conditional variance of FIGARCH 


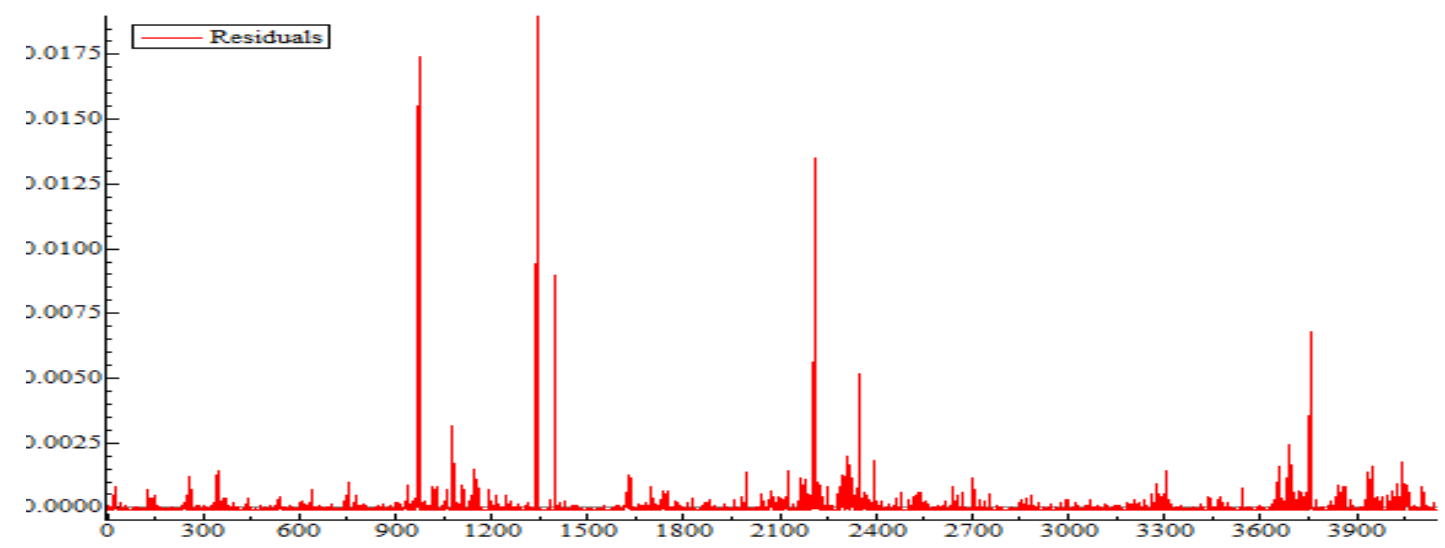

Figure16. Residual of HYGARCH

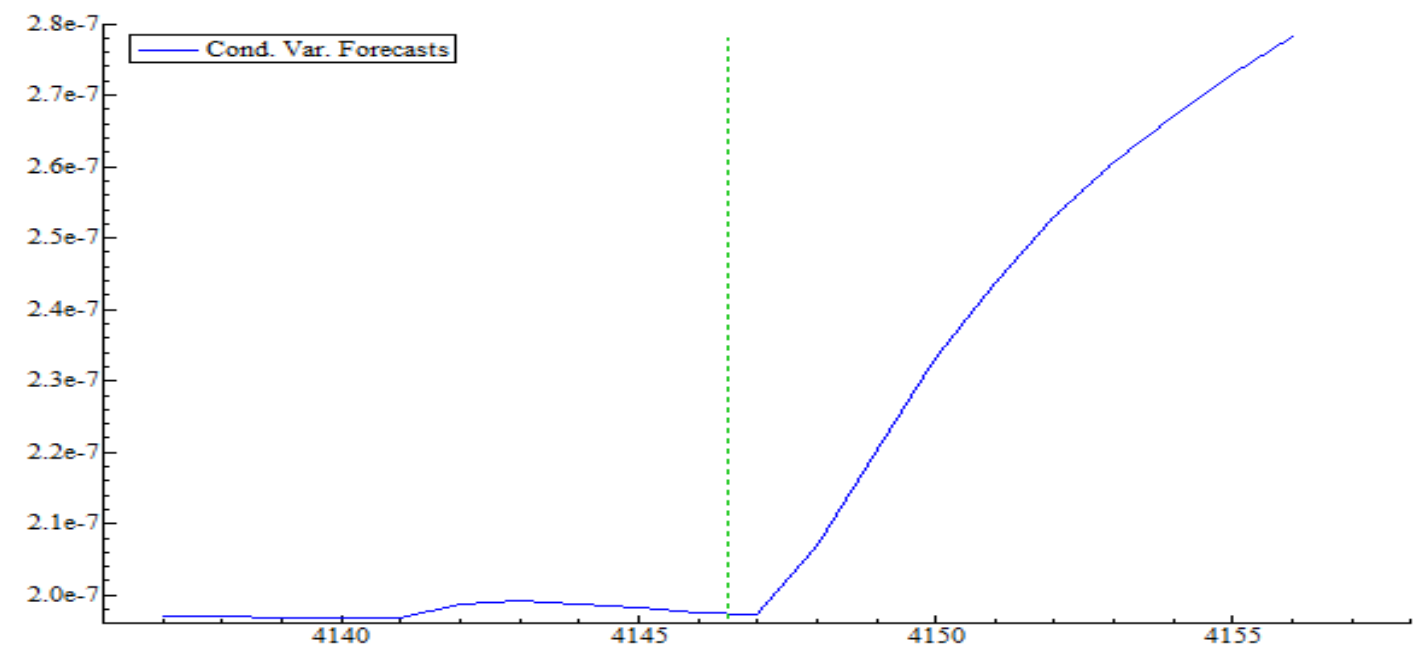

Figure 17. Conditional variance of HYGARCH article distributed under the terms and conditions of the Creative Commons Attribution (CC BY) license (http://creativecommons.org/licenses/by/4.0/). 